\title{
The Key Problems and Solutions of the New Generation BRT in China
}

\author{
Zhong GUO \\ China Academy of Transport Sciences \\ CUSTReC \\ Beijing, China \\ e-mail: gz7811982@163.com
}

\author{
Xiao PENG \\ China Academy of Transport Sciences \\ CUSTReC \\ Beijing, China \\ e-mail: gistiger@163.com
}

\begin{abstract}
Over the last ten years, Bus Rapid Transit (BRT) has expanded faster than in any other region, with $3000 \mathrm{~km}$ of BRT systems opened in $\mathbf{2 5}$ cities. The paper firstly introduced the features and models of Bus Rapid Transit (BRT). Then it introduced the development of BRT in China, and summarizes the key problem planning, designing, operation and management of BRT. Finally the paper finishes with a summary of key lessons learned for the new generation BRT, and attempts to provide policy recommendations for cities in where BRT is going to be constructed or being constructing.
\end{abstract}

Keywords-bus rapid transit; the key problem; new generation $B R T$; policy recommendations

\section{INTRODUCTION}

BRT which is originated in the middle of 1970 is a rapid public transit system which is between urban railway system and traditional bus system. Compared to subway and light rail, BRT has many advantages, less investment, short construction cycle, great capacity, rapid speed, less pollution and so on. In recent years, under the influence of the successful abroad BRT projects, it inspired many cities to plan and construct BRT. Therefore it has practical significance to strengthen the research of Bus Rapid Transit System, and needs theory and research findings to put BRT into practice, fully displaying effectiveness of BRT [1].

\section{A. Features of BRT}

A BRT system is not simply an exclusive bus route; it is an integration of multiple elements, including the stops, vehicles, routes, bus lanes and intelligent bus systems, boasting the following features [2]- [4].

- Fast operating speed: on a dedicated lane, BRT vehicles usually operate at a speed of $20-35 \mathrm{~km} / \mathrm{h}$ on an exclusive right of way, which is close to the operating speed of rail transit.

- Strong operating capacity: in peak hours, the oneway transport capacity can reach 15,000 to 25,000 passengers per hour in general, equivalent to that of middle-volume rail transit. A high-standard BRT system can expect a transport capacity of over 40,000 passengers per hour, approximating, if not surpassing, the vast majority of rail transit capacity.

- High service capacity: in majority of the systems, the new-type articulated vehicles of 18 to 25 meters long are adopted, each vehicle can carry 200 250 passengers.

- $\quad$ BRT vehicles are usually uniform, brightly coloured and identically marked for branding purposes.

\section{B. Typical development models of BRT in China}

China is seeing its cities striving to find their own approaches to BRT based on local characteristics and development needs, which basically fall to three BRT corridor categories: closed, open-ended and mixed [5].

\section{DEVELOPMENT AND PROBLEM OF BRT IN CHINA}

\section{A. The Development of BRT in China}

China's BRT system study began in the late twentieth century. In 1999, the first central bus lane was built in Beijing Road of Kunming City (the most important passenger transport corridor), being the prototype of BRT. Since 2002, a number of international experts and institutions began to publicize advanced concepts of BRT in China. In March 2003, Beijing Municipal Commission of Transport held a seminar on the development strategy for BRT in Beijing, discussing the necessity and feasibility for the inception of BRT projects in the city. At the end of 2005, the South-axis BRT project was completed and put into operation, being China's first complete BRT system in a real sense. By the end of 2015, the country saw BRT systems running in 25 cities, with more cities engaged in their planning, design and construction of BRT systems.

As of 2015, the average daily ridership of BRT in China reached 3.91 million, of which Guangzhou and Zhengzhou accounted for the highest portion, both at 680,000 passengers per day, followed by Xiamen at 369,000 passengers per day [6]-[7].

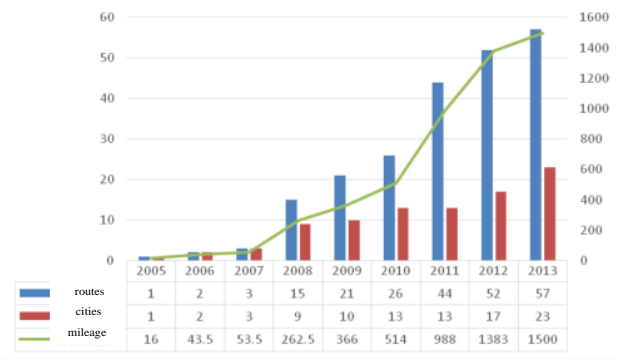

Figure 1. The development of BRT over the years in China 
TABLE I. AVERAGE DAILy BRT RIDERShIP IN 24 CITIES NATIONWIDE

\begin{tabular}{|l|l|l|l|}
\hline \multicolumn{1}{|c|}{ City } & $\begin{array}{c}\text { BRT ridership } \\
\text { (10,000 } \\
\text { passengers per } \\
\text { day) }\end{array}$ & \multicolumn{1}{|c|}{ City } & $\begin{array}{c}\text { BRT ridership } \\
\text { (10,000 } \\
\text { passengers per } \\
\text { day) }\end{array}$ \\
\hline Beijing & 16.73 & Zaozhuang & 4.83 \\
\hline Dalian & 5.00 & Jining & 0.25 \\
\hline Changzhou & 28.59 & Zhengzhou & 68.14 \\
\hline Lianyungang & 8.46 & Yichang & 3.34 \\
\hline Yancheng & 10.27 & Changde & 3.07 \\
\hline Hangzhou & 12.48 & Guangzhou & 68.22 \\
\hline Shaoxing & 1.16 & Zhongshan & 3.30 \\
\hline Jinhua & 0.21 & Liuzhou & 9.96 \\
\hline Zhoushan & 1.09 & Chengdu & 27.82 \\
\hline Hefei & 15.53 & Lanzhou & 11.25 \\
\hline Xiamen & 36.95 & Yinchuan & 9.54 \\
\hline Jinan & 10.31 & Urumqi & 35.23 \\
\hline
\end{tabular}

\section{B. Problems with the Development of BRT}

- Ambiguity in the selection and functionality of BRT.BRT planning and construction has drawn attention from many cities, and in practice there are obvious concerns about the functional orientation of BRT, which leads to failures in proposing a BRT model in line with urban development. In China, among the cities possessing or planning to introduce BRT systems, some have established rail transit, some see their rail transit under construction, some are planning to do the work, and some even do not have a plan. In developing the BRT, a portion of the cities have not identified the short-term and longterm functionality of BRT in their local urban transit.

- Not reasonable in Channel and platform. Some sections along the busway lack the designed roadcenter segmentation. As a result, massive motor vehicles can turn around, vehicles coming out of and going into roadside buildings can turn left and cut across straight traffic, not to mention the crossing pedestrians and bicycles and other sources of transverse interference, which severely handicap the efficient operation of vehicles in the busway, especially at rush hours, and is likely to cause traffic chaos and accidents. When the BRT system is introduced into the city, we need to develop new charge models. In the context of integrated public transport development in big cities, charge models should be developed based on BRT's inherent characteristics as well as on the need for coordinated services between BRT and conventional bus/rail transit. A flat fare scheme is necessary for the integrated utilization of public transport resources.

- Poor coordination between BRT and other means of passenger transport. We are not yet fully aware of the collaboration and conflicts between BRT and other means of transport. From a global point of view, different means of transport assume different roles in the city, jointly guiding and forming the integrated and effective architecture for urban transport and travel. Therefore, from the perspective of the city, different means of transport are collaboratively complementary to each other; In view of the common traffic along the urban passenger corridor shared by different means of transport, they actually compete for interests. Unlike rail transit, BRT will have a direct impact on the existing road network and the established conventional bus network. Isolated design, construction and operation of BRT without taking into account the associated problems will not only affect other means of transport but also jeopardize BRT itself.

- Application of the BRT bus-priority signal technology. An important measure to improve the operating efficiency of BRT busways and the attractiveness of BRT in Chinese cities is the analysis and study of busway phase setting and inductive bus-priority signals based on the settings of dedicated busways, bus-only access at intersections and specific conditions of intersections. So far, no city has fully internalized bus signal priority. To realize this vision, we first need a traffic control center to enforce signal priority according to the road conditions, and then need interactions between the buses and the signal controller so that the green light will be on when a bus arrives. Busways only guarantee the traveling speed of vehicles on a dedicated lane, and if there is no signal priority and the intersections become busy, the whole operating speed will be hindered. BRT routes are generally set at trunk roads with considerable traffic, where traffic light interval at every intersection is longer, and a BRT vehicle will never run fast if each intersection costs 1 minute or more for passage.

TABLE II. PROPORTIONS OF DEDICATED BUS LANES IN THE BRT CORRIDOR

\begin{tabular}{|c|c|c|c|}
\hline City & $\begin{array}{c}\text { Proportion } \\
\text { of dedicated } \\
\text { bus lanes in } \\
\text { the BRT } \\
\text { corridor }\end{array}$ & City & $\begin{array}{c}\text { Proportion of } \\
\text { dedicated bus } \\
\text { lanes in the BRT } \\
\text { corridor }\end{array}$ \\
\hline Beijing & 0.75 & Jinan & 0.87 \\
\hline Dalian & 0.66 & Zhengzhou & 0.68 \\
\hline Changzhou & 0.96 & Yichang & 0.62 \\
\hline Lianyungang & 1.00 & Changde & 1.00 \\
\hline Yancheng & 1.00 & Guangzhou & 1.00 \\
\hline Hangzhou & 0.51 & Zhongshan & 0.97 \\
\hline Shaoxing & 0.61 & Chengdu & 1.00 \\
\hline Zhoushan & 0.85 & Lanzhou & 0.95 \\
\hline Hefei & 1.00 & Yinchuan & 1.00 \\
\hline Xiamen & 0.98 & Urumqi & 0.55 \\
\hline
\end{tabular}




\section{RECOMMENDATIONS FOR THE BRT DEVELOPMENT}

BRT systems are growing rapidly in China, but still lagging far behind those in foreign cities. To level up China's BRT systems, the Chinese cities need to make efforts in four aspects: planning, construction, management and policy.

\section{A. Rational Selection of the Right-of-way Model Based on} Localities

BRT routes generally go through the main passenger corridor of a city. With so many vehicles, the right of way is the core of competition for interests. Therefore, it is crucial to choose the appropriate right-of-way model. In some economically developed metropolitans, along the roads on which BRT routes operate, long-term passenger demand is estimated to be equivalent to rail transit demand, with the ground vehicle traffic approaching saturation. Ground roads may not be able to afford dedicated busways (lacking reconstruction conditions), and we should consider setting an independent right-of-way model, such as the elevated BRT model in Xiamen. In other cities, ground dedicated busways should be maximized as long as ground conditions permit to reduce project cost.

\section{B. Good Business Planning and Rational Site Selection}

Since BRT is a large-capacity public transport means, it is a real cardiac for land development along the road on both sides. So, at the stage of BRT mesh planning, a detailed business plan should be made based on the overall planning of the city, with the station sites selected in an appropriate manner, facilitating the development of the city and increasing the revenue of BRT operators.

\section{Properly Handled Convergence and Transfer between the BRT and Other Means of Transport}

As an alternative in the urban public transport system, BRT should be included in the overall planning of urban transit network rather than segregated from rails, conventional buses and other public transport means. A decisive factor for the success of BRT is the planning for coordinated BRT with the network of conventional buses, rails and pedestrians and bicycles, which will create easy transfer between BRT vehicles as well as between BRT and other means of transport.

\section{Well-designed Station Area}

In most cases, the key factor for setting up a high-speed, large-capacity system lies in reducing the crowded area at the station. Currently, BRT systems are comparable to subway systems (high-end, super-capacity subway systems excluded) in terms of speed and capacity, mainly owing to greatly enhanced capacity at the station. Other factors also play an important role in achieving the goal of high speed and large capacity, but none is as critical as solving the congestion at the berth. To design an effective BRT system, we need to get a thorough understanding of the causes of berth congestion and the solutions. Underspend troubles many existing BRT systems due to inaccurate forecasts on the demand of specific stations. System design inappropriateness may result in a peak-hour queue, creating a fleet up to several hundred meters long. Therefore, we need to accurately predict future ridership, and on this basis properly design the number of berths and the setting of the passing lane at each station.

\section{E. Rational Integration of the Components of the Public Transport System}

Improvement in the outreach and quality of BRT services stems from the integration of the entire system, namely: compared to conventional ground public transit, the BRT system has integrated BRT busway lanes, well-equipped stations, advanced fare collection and validation systems, ameliorated vehicles, intelligent information systems and operational organization, thus making a qualitative leap forward in service with enhanced operating speed, reliability, comfort and throughput.

Nevertheless, a city should integrate the above six elements with priority and order based on its own conditions of roads, transport and traffic, as well as its financial affordability. First of all, we must ensure that BRT can operate in an independent space (busway), with improved vehicles and stations possessing ticketing systems, which guarantees the operating speed, passenger throughput, security and reliability. Next, we can improve the elements affecting passage capacity according to the needs of throughput.

\section{F. Great Efforts to be Made for Promoting Non-motorized Feeders in Urban Areas where Inadequate Road Resources Struggle to Fulfill Massive Passenger Demand}

There should be supporting transport systems for distribution on the periphery of BRT stations. To build a low-carbon city, we should maximize the advantages of nonmotor vehicles and pedestrians around the stations where limited road resources shall be maximized to accommodate large passenger flows, improving the service efficiency of BRT stations.

- Parking facilities and dedicated lanes for non-motor vehicles should be established on the BRT periphery of BRT stations, attracting passengers to adopt nonmotorized feeders.

- Public bicycle service systems should be developed within the CBD to meet the specific needs of each city, with bike rental stands set up at each BRT station.

\section{G. More intensive, Broader and In-depth Publicity Campaigns for BRT}

The key to BRT promotion lies in changes in the mindset. The alignment of BRT busway is the redistribution of road resources, which belong to public resources. So it is about whether the right of way should be allocated to the majority or minority of people. If we do not change the wrong, obsolete perception that urban road resources should be allocated according to the number of operating vehicles, and if we fail to find out the rational right-of-way allocation, BRT will inevitably be subject to criticism and censure from different interest groups. Therefore, society-wide education 
and publicity campaigns should be launched to get the public fully aware of the significance of developing BRT systems.

In its early days in China, BRT was promoted to policy makers and practitioners in the transport sector alone. However, as domestic cities have successively set up or planned for their own BRT routes and meshes, such publicity seems insufficient regarding its strength, outreach and influence: publicity targeted at mere policy makers and the transport sector is far from satisfactory, and we should internalize BRT into the public mind. Practices in cities over the past few years reveal that the lack of technical BRT knowledge reserve constitutes a bottleneck in BRT project execution. It is common that the technical personnel responsible for the implementation begin to collect data and get the technical knowledge of BRT after policy makers have decided to develop the BRT system. In view of this scenario, we should reinforce the technical publicity.

\section{CONCLUSION}

China introduced BRT systems to Beijing in December 2004, which was put into operation successfully in the following December 2005. Then, many cities began to build their own BRT systems. As of the end of 2015, BRT routes were operating in 25 cities, and the length of BRT lanes totaled 2,991 km, with 6,146 vehicles carrying $1,429,830,000$ passengers throughout the year. Some key problem exist in development of china such as, Ambiguity in the selection and functionality of BRT, Poor coordination between BRT and other means of passenger transport and
Channel, the platform were designed not reasonable, restricting the development of BRT. So it is necessary to make efforts in four aspects: planning, construction, management and policy.

\section{ACKNOWLEDGEMENTS}

This work was financially supported by the Volvo Research and Educational Foundations (Project No.CoE2005-3), and the Projects of the National Natural Science Fund Committee "Research on Urban space based on different scales of heterogeneity effect on urban public transportation" (41471459).

\section{REFERENCES}

[1] Duoquan, W. Study on operations management system technology of BRT.Southwest Jiaotong University, 2008

[2] Dong, X. Smooth connection between bus rapid transit and regular bus transit. Chengdu: Southwest Jiaotong University, 2011.

[3] Xiaoguo, Z. Research on coordination of bus transit rapid and ragular bus. Changsha: Changsha University of Science and Technology, 2009.

[4] Wang, S., L. Sun, and J. Rong. Research on influence area of rail transit stations in Beijing City. Journal of Transportation Systems Engineering and Information Technology, Vol. 13, No. 3, 2013, pp. 184-185.

[5] Xiaoqing L.,Panyu Y. research on the adaptability of operation mode about Bus Rapid Transit. Journal of Standardization of Traffic, No.17, 2009

[6] YuLin, J.Annual Report of Urban Passenger Transport, 2014.

[7] URL: http://www.itdp-china.org/indexlang/?lang=0 